\title{
Perbandingan Pengaruh Pemberian Jus Semangka dan Minuman Isotonik terhadap Status Hidrasi Atlet Futsal
}

\author{
Lutvida Hesti Rismawati ${ }^{\bowtie}$ Imas Damayanti, Iman Imanudin \\ Program Studi Ilmu keolahragaan, Departemen Pendidikan Kesehatan dan Rekreasi, Fakultas \\ Pendidikan Olahraga dan Kesehatan, Universitas Pendidikan Indonesia, Indonesia
}

\begin{tabular}{l}
\hline Info Artikel \\
\hline Sejarah Artikel: \\
Diterima: Mei-2018 \\
Disetujui: Mei-2018 \\
Dipublikasikan : Mei-2018 \\
\hline Kata Kunci: \\
watermelon, isotonic drink, training, \\
hydration status \\
\hline
\end{tabular}

hydration status

\begin{abstract}
Abstrak
Status hidrasi merupakan salah satu faktor yang mempengaruhi kerja fisik atlet futsal. Komposisi cairan elektrolit yang seimbang dan jumlah yang cukup akan dapat menjaga status hidrasi atlet. Hal tersebut diantisipasi dengan menggunakan bahan alami sebagai minuman olahraga. Buah semangka merupakan buah yang mengandung banyak sekali kandungan air. Tujuan dari penelitian ini adalah untuk mengetahui pengaruh pemberian jus semangka dan minuman isotonik yang di kombinasikan dengan program latihan futsal. 10 orang atlet futsal putra Kota Cimahi berpartisipasi sebagai sampel dalam penelitian ini. Metode yang digunakan yaitu metode eksperimen dengan desain penelitian $2 \times 2$ cross over design. Penelitian ini terbagi menjadi 2 periode dengan masing-masing periode dilakukan 3 kali percobaan dengan masa washout 2 hari. Sampel dibagi 2 kelompok dengan kelompok 1 diberi treatment jus semangka dan kelompok 2 diberi minuman isotonik lalu pada periode selanjutnya disilangkan. Jus semangka dan minuman isotonik diminum setiap 20 menit sekali selama 2 jam latihan. Instrumen pengambilan data menggunakan Urinalysis Multisticks Urine Strip Test Stick Strips dengan metode pengukuran berat jenis urin. Hasil dari penelitian ini menunjukan tidak ada perbedaan nilai rata-rata antara sebelum dan sesudah treatment pada kedua minuman $(p>0,05)$. Dari hasil tersebut dapat disimpulkan bahwa pemberian jus semangka dan minuman isotonik dapat mencegah terjadinya dehidrasi.
\end{abstract}

\begin{abstract}
The purpose for this research is that to understand the effect of watermelon juice and isotonic drink which combined with the futsal training program. 10 male futsal athlete from Cimahi City participated as samples in this research. The method that used is experiment with research design $2 \times 2$ cross over design. This research divided in 2 period 3 times trial with 2 days wash out in each of those period. Samples divided in 2 groups with 1 st group was given watermelon juice treatment and 2 sd group was isotonic drink, and the next period each of group exchange their drinks treatment. Watermelon and isotonic drink absorb every 20 minutes for 2 hours practice. The instrument of data collection using Urinalysis Multi sticks Urine Strip Test Stick strips with measurement of urine specific gravity. The result of this research shows there are no much significant overage percentage between before and after the treatment to both drinks $(p>0,05)$ from the result can be condude that distributing watermelon juice and isotonic drink can prevent dehydration.
\end{abstract}

(C) 2018 Universitas Pendidikan Indonesia 


\section{PENDAHULUAN}

Olahraga futsal merupakan variasi dari olahraga sepakbola dengan bola yang digunakan lebih kecil dan berat dan olahraga futsal memerlukan persiapan latihan fisik yang baik agar mencapai prestasi maksimal (Hermans, Gdawietz, Engler, \& Schwehm, 2010; Lhaksana, 2011; Murhananto, 2006). Seorang atlet futsal harus memiliki kecepatan ,kelincahan, daya tahan, kekuatan dan fleksibilitas yang baik agar menunjang selama latihan dan pertandingan. Ketika seseorang yang sedang melakukan latihan fisik akan terjadi peningkatan aktivitas otot rangka dan peningkatan metabolisme energi (Hidayat, 2014) . Begitu pula dengan keringat yang keluar, pelepasan keringat tak hanya akan kehilangan air saja, akan tetapi dalam kondisi tertentu dapat pula terjadi peningkatan pengeluaran elektrolit utama seperti sodium (natrium) dan klor atau garam tergantung pada intensitas latihan, faktor individu, kondisi lingkungan, dan status hidrasi (Dwita, Amalia, Iwo, \& Bahri, 2015; Hidayat, 2014)

Seorang atlet yang telah mengalami dehidrasi tidak akan bisa menjalankan masa latihan ataupun pertandingan dengan baik dan ini akibat dari rehidrasi tubuh yang buruk di dalam tubuh. Pengaturan asupan cairan merupakan salah satu cara untuk menghindari terjadinya dehidrasi karena pada saat olahraga tubuh akan membutuhkan cairan dan karbohidrat yang dapat dipenuhi melalui konsumsi 600-1.500 $\mathrm{ml}$ air putih yang ditambahkan 24-100 gr karbohidrat (4-7\% larutan karbohidrat) tiap jamnya yang bisa diperoleh dari minuman yang mengandung karbohidrat dan elektrolit, diantaranta jus buah, jus sayur, susu, dan sport drink (Dieny \& Putriana, 2015; Irawan, 2007).

Shalesh, Hasan, \& Jaaz (2014) meneliti tentang efek sport drink pada beberapa variabel fungsional untuk pemain sepak bola selama kerja aerobik dengan intensitas yang progresif menggunakan treadmill, perekaman detak jantung, tekanan darah dan elektrolit darah (ion natrium, ion kalium) sebelum dan setelah berlari. Penelitian ini membandingkan antara sport drink dengan air putih, dan hasilnya ada perbedaan yang signifikan antara minuman air putih dengan minuman olahraga.

Alternatif lain untuk memasok karbohidrat dan cairan untuk tubuh adalah kombinasi buah segar dan air putih. Pilih buah segar (pepaya, semangka, pisang, kismis) yang dapat diserap tubuh dengan cepat sehingga lebih optimal dalam menggantikan energi setelah olahraga (Dieny \& Putriana, 2015; Farrow \& Mujika, 2007).

Dari pernyataan tersebut beberapa buah dapat digunakan untuk menjadi rekomendasi dalam menggantikan karbohidrat dan cairan untuk tubuh salah satunya yaitu semangka. Telah banyak penelitian buah semangka dan hasilnya terdapat efek yang signifikan pemberian jus semangka terhadap kelelahan otot, kelelahan anaerobik, denyut nadi, delayed onset muscle soreness, dan VO2Max (Hasanah, 2015; Lubis \& Siregar, 2017; Setiawan, 2016; Sirait et al., 2015). Arifianto (2008) mengungkapkan bahwa di dalam 100 gram buah semangka memiliki kandungan air sebanyak $92,1 \%$ dan kandungan karbohidrat 6,9 gr. Kombinasi kandungan air dan karbohidrat pada buah semangka bisa menjadi alternatif baru untuk menjaga status hidrasi. Akan tetapi, belum terdapat penelitian mengenai pengaruh dari pemberian buah semangka terhadap status hidrasi atlet. Maka dari itu, diperlukan adanya penelitian mengenai hal tersebut. Sehingga dapat diperoleh informasi khususnya pelaku olahraga tentang bagaimana agar atlet-atletnya terhindar dari bahaya dehidrasi dengan cara sehat dan alami, serta dapat mengurangi konsumsi minuman-minuman yang cenderung banyak mengandung zat-zat kimia yang dapat membahayakan atlet itu sendiri.

\section{METODE}

Metode penelitian yang digunakan adalah metode eksperimen dengan menggunakan 2x2 crossover design (Jones \& Kenward, 2014). Terdapat 2 kelompok yaitu kelompok treatment 1 dan kelompok treatment 2 . 


\section{Partisipan}

Sebanyak 10 orang atlet futsal putra berusia ratarata 20.5 thn pelatcab Kota Cimahi diambil secara simple random sampling untuk menjadi partisipan dalam penelitian ini (Sugiyono, 2016)

\section{Instrumen}

Instrumen pada penelitian ini menggunakan Mission 10 Parameter Professional/GP Urinalysis Multisticks Strip Test Stick Strips. Alat yang digunakan untuk pengambilan data yaitu gelas plastik, Masker, Sarung tangan, dan timbangan digital

\section{Bahan}

bahan yang digunakan yaitu dalam penelitian ini yaitu buah semangka (Citrullus lanatus) lokal yang berusia \pm 3 bulan. Buah semangka tersebut di blender tanpa campuran apapun (Junaidi, 2013). Minuman isotonik berupa pocari sweat yang merupakan minuman isotonik yang dibuat untuk mengganti cairan tubuh yang hilang, di produksi oleh PT. Amerta Indah Otsuka sejak 1991.

\section{Prosedur Perlakuan}

Penelitian ini dilakukan selama 2 periode dengan setiap periode dilakukan percobaan sebanyak tiga kali dan masa washout dua hari (Dwita et al., 2015; Zanzer, 2011). Dua jam sebelum perlakuan, tiap atlet diberi $500 \mathrm{ml}$ air putih dan 20 menit sebelum perlakuan diberikan lagi sebanyak $200 \mathrm{ml}$ yang bertujuan untuk mengkondisikan status hidrasi atlet untuk optimasi rehidrasi (Dwita et al., 2015). Sebelum diberikan perlakuan atlet melakukan pre test dengan pengambilan air urin. Selanjutnya para atlet akan diberikan latihan selama 2 jam dan kelompok treatment 1 akan diberikan treatment 1 berupa jus semangka dan kelompok treatment 2 akan diberikan treatment 2 berupa minuman isotonik setiap 20 menit sekali. Selanjutnya setelah latihan selesai atlet melakukan post test dengan pengambilan air urin kembali. Setelah periode 1 selesai, maka akan diakukan masa washout selama 2 hari dan dilakukan penyilangan pemberian treatment. Keefektifan dari 2 minuman ini ditentukan melalui penilaian berat jenis urin.

\section{Penentuan Berat Jenis Urin}

Penentuan berat jenis urin dilakukan untuk melihat secara objektif status hidrasi seseorang. Urin akan ditampung di dalam gelas kering dan bersih, lalu stick urin akan dicelupkan ke dalam gelas tersebut hingga seluruh stick urin basah oleh air urin lalu angkat dan simpan di tempat kering. Selanjutnya, tunggu hingga 1-2 menit sampai warna pada stick urin berubah. Setelah itu,warna pada stick urin diamati dan dibandingkan dengan warna standar yang ada pada kemasan lalu dicatat hasilnya.

Sulistomo, Sutarina, \& Ilyas (2014) dalam keadaan normal berat jenis berkisar 1.010-1.030 tetapi bila berat jenis lebih besar dari 1.030 perlu dicurigai terjadinya kekurangan cairan tubuh. Menurut (Dieny \& Putriana, 2015)tingkatan status hidrasi secara rinci dilihat dari berat jenis urin adalah sebagai berikut;

Tabel 1. Tingkatan Status Hidrasi

\begin{tabular}{cc}
\hline Status Hidrasi & Nilai Berat Jenis Urin \\
\hline well-hydrated & $<1.010 \mathrm{~g} / \mathrm{dl}$ \\
minimal dehydration & $<1.010-1.020 \mathrm{~g} / \mathrm{dl}$ \\
significant dehydration & $1.021-1.030 \mathrm{~g} / \mathrm{dl}$ \\
seriously dehydration & $>1.030 \mathrm{~g} / \mathrm{dl}$ \\
\hline
\end{tabular}

Sumber : (Dieny \& Putriana, 2015)

\section{Analisis Data}

Data yang diperoleh dianalisis secara statistik menggunakan perangkat lunak (software) yakni Statistical Package for Social Science (SPSS) versi 22 menggunakan Paired Sample T-Test dan TIndependent-Sample Test. Penulisan rujukan dibantu oleh perangkat lunak (software) mendeley dekstop.

\section{HASIL}

Penelitian ini dilakukan untuk mengetahui bagaimana efek dari 2 minuman untuk menjaga status hidrasi selama masa latihan. Karakteristik sampel tersaji dalam tabel 2. dengan menjelaskan beberapa variabel karakteristik seperti; usia, berat badan, tinggi badan, dan BMI. 
Tabel 2. Karakteristik Subyek

\begin{tabular}{cccccc}
\hline Variabel & N & Min & Max & Mean & Std. Dev \\
\hline Usia & 10 & 15 & 19 & 17,4 & 1,34 \\
Berat Badan & 10 & 49 & 75 & 56,9 & 7,86 \\
Tinggi Badan & 10 & 159 & 171 & 165,9 & 4,17 \\
BMI & 10 & 18,87 & 26,25 & 20,6 & 2,21 \\
\hline
\end{tabular}

Tabel 3. Statistika Deskriptif

\begin{tabular}{cccccr}
\hline Berat Jenis Urin & N & Min & Max & Mean & Std. Dev \\
\hline jus semangka pre test & 10 & $1.003,33$ & $1.015,00$ & $1.010,00$ & 3,85 \\
jus semangka post test & 10 & $1.000,00$ & $1.018,33$ & $1.008,83$ & 5,45 \\
minuman isotonik pre test & 10 & $1.001,67$ & $1.021,67$ & $1.012,67$ & 6,77 \\
minuman isotonik post test & 10 & $1.003,33$ & $1.021,67$ & $1.013,99$ & 5,73 \\
\hline
\end{tabular}

Tabel 4. Paired Sampel T-Test \& Independent Sampel T-Test

\begin{tabular}{ccccccc}
\hline Berat Jenis Urin & $\mathbf{N}$ & $\begin{array}{c}\text { Pre-Test } \\
\text { (Mean } \pm \text { SD) }\end{array}$ & $\begin{array}{c}\text { Post-Test } \\
\text { (Mean } \pm \text { SEM) }\end{array}$ & P-Value & $\begin{array}{c}\text { Gain } \\
\text { (Mean } \pm \text { SD) }\end{array}$ & P-Value \\
\hline Jus Semangka & 10 & $1.010,00 \pm 3,85$ & $1.008,83 \pm 5,45$ & 0,363 & $-1,167 \pm 3,85$ & 0,461 \\
Minuman Isotonik & 10 & $1.012,67 \pm 6,77$ & $1.013,99 \pm 5,73$ & 0,388 & $1,332 \pm 4,63$ & \\
\hline
\end{tabular}

Usia minimal berada pada angka 15 tahun sedangkan angka maksimalnya berada pada usia 19 tahun dengan rata-rata usia 17,4 tahun dan standar deviasi sebesar 1,35. Berat badan minimal berada pada angka $49 \mathrm{~kg}$ sedangkan angka maksimalnya sebesar $75 \mathrm{~kg}$ dengan rata-rata berat badan $56,9 \mathrm{~kg}$ dan standar deviasi sebesar 7,87. Tinggi badan minimal berada pada angka $159 \mathrm{~cm}$ sedangkan angka maksimalnya sebesar $171 \mathrm{~cm}$ dengan rata-rata tinggi badan sebesar $165,9 \mathrm{~cm}$ dan standar deviasi 4,18. BMI minimal berada pada angka $18,87 \mathrm{~kg} / \mathrm{m}^{2}$ sedangkan angka maksimalnya sebesar $26,25 \mathrm{~kg} / \mathrm{m}^{2}$ dengan rata-rata BMI 20,62 $\mathrm{kg} / \mathrm{m}^{2}$ dan standar deviasi sebesar 2,21.

Berdasarkan tabel 3. diketahui bahwa keseluruhan jumlah sampel dari setiap variabel yakni $\mathrm{N}=10$. Variabel BJU Jus Semangka Pre Test memiliki Mean sebesar 1.010,00 dengan standar deviasi sebesar 3,85. Variabel BJU Jus Semangka Post Test memiliki Mean 1.008,83 dengan standar deviasi sebesar 5,45. Variabel BJU Minuman Isotonik Pre Test memiliki Mean
1.012,67 dengan standar deviasi sebesar 6,77. Variabel BJU Minuman Isotonik Post Test memiliki Mean 1.013,99 dengan standar deviasi sebesar 5,73.

Setelah melakukan penelitian perbandingan pengaruh jus semangka dan minuman isotonik terhadap status hidrasi atlet futsal, dan setelah mengolah data didapatkan hasil sebagai berikut :

Pada tabel 3. menunjukan berat jenis urin jus semangka Pre Test memiliki Mean $\pm S D$ sebesar 1.010,00 $\pm 3,85$ dan berat jenis urin jus semangka Post Test memiliki Mean $\pm S D 1.008,83$ $\pm 5,45$ nilai signifikansi sebesar $p=0,363$ dan menunjukkan nilai gain hitung sebesar $1,167 \pm 3,85$. Berat jenis urin minuman isotonik Pre Test memiliki Mean $\pm S D$ sebesar 1.012,67 \pm 6,77 dan berat jenis urin minuman isotonik Post Test memiliki Mean $\pm S D$ 1.013,99 \pm 5,73 nilai signifikansi sebesar $\mathrm{p}=0,363$ dan menunjukkan nilai gain hitung sebesar $1,332 \pm 4,63$. Taraf signifikansi lebih dari nilai alpha $(\mathrm{p}>0,05)$ dan dapat ditarik kesimpulan bahwa $\mathrm{H}_{0}$ diterima dan 
dapat diinterpretasikan bahwa tidak ada perbedaan rata-rata berat jenis urin sebelum dan sesudah diberi treatment. Hal ini menunjukkan bahwa adanya pengaruh jus semangka dan minuman isotonik dalam menjaga status hidrasi dan mencegah terjadinya dehidrasi. Gain menunjukkan nilai sebesar 0,461 atau lebih besar dari nilai alpha dan dapat disimpulkan tidak terdapat perbedaan yang signifikan antara jus semangka dan minuman isotonik.

\section{PEMBAHASAN}

Hidayat (2014) menyatakan bahwa ketika seseorang melakukan latihan fisik, terjadi peningkatan aktivitas otot rangka, yang membutuhkan energi lebih dengan peningkatan metabolisme (pembentukan) energi. Peningkatan metabolisme energi akan meningkatkan produksi panas tubuh. Panas tubuh harus dikendalikan agar fungsi seluruh tubuh tetap dalam batas yang dapat ditoleransi sel, organ dan sistem organ, adalah dengan mengendalikan/menurunkan suhu tubuh yang meningkat melalui pelepasan panas tubuh dan berkeringat. Mekanisme pelepasan panas sangat penting, apalagi dalam olahraga. Secara teoritis saat kita melakukan excersise, panas produksi dapat mencapai 1-20 F setiap 5 menit, yang berarti cairan tubuh kita dapat benar-benar mendidih jika panas tidak dirilis (Damayanti, I., \& Rahayu, 2017).

Tubuh seacara alami melepaskan panas melalui radiasi, konduksi, konveksi dan penguapan (Katch, Katch, \& McArdle, 1994). Cara utama fisiologis untuk melepaskan panas tubuh adalah evaporasi, ada satu hingga empat kelenjar keringat milliom yang tersebar di seluruh permukaan tubuh dan ketika menanggapi panas, kelenjar ini akan menghasilkan keringat sebagai respon terhadap panas, kerikunan ini akan memproduksi sejumlah besar keringat (Damayanti, I., \& Rahayu, 2017). Efek Pendingin akan terjadi ketika keringat menguap dan kulit dingin akan mendinginkan lapisan dalam lainnya kulit melalui pembuluh darah yang lewat (Katch et al., 1994). Ketika tubuh melakukan pekerjaan fisik yang berat, seperti olahraga dengan intensitas tinggi, seseorang dapat menghasilkan 2 liter keringat dari cairan tubuh. Pada atlet ketahanan, kehilangan $4 \%$ berat badan tidak jarang terjadi dalam pelatihan. Jumlah ini tergantung pada intensitas dan durasi olahraga serta kondisi lingkungan.

Pelepasan keringat tak hanya akan kehilangan air saja, akan tetapi dalam kondisi tertentu dapat pula terjadi peningkatan pengeluaran elektrolit utama seperti sodium (natrium) dan klor atau garam (Hidayat, 2014). Ketika pengeluaran keringat terjadi secara berlebihan, tubuh akan mengalami dehidrasi akibat kehilangan banyak cairan tubuh dan elektrolit. Banyaknya cairan tubuh yang hilang melalui keringat tergantung pada intensitas latihan, faktor individu, kondisi lingkungan, dan status hidrasi (Dwita et al., 2015)

Seorang atlet yang telah mengalami dehidrasi tidak akan bisa menjalankan masa latihan ataupun pertandingan dengan baik. perfomance atlet tersebut akan menurun dan prestasi pun sulit diraih. Dehidrasi terjadi akibat rehidrasi tubuh yang buruk di dalam tubuh. Pengaturan asupan cairan merupakan salah satu cara untuk menghindari terjadinya dehidrasi karena pada saat olahraga tubuh akan membutuhkan cairan agar terhindar dari dehidrasi, kebutuhan karbohidrat dapat dipenuhi melalui konsumsi $600-1.500 \mathrm{ml}$ air putih yang ditambahkan 24-100 gr karbohidrat (4-7\% larutan karbohidrat) tiap jamnya (Irawan, 2007) . Dari pernyataan tersebut dapat disimpulkan bahwa pemberian cairan dan karbohidrat merupakan salah satu cara untuk merehidrasi tubuh agar tidak terjadi dehidrasi. Untuk mengatasi agar tidak terjadinya dehidrasi, maka diperlukan asupan cairan sebagai pengganti cairan tubuh yang hilang. Hal tersebut dilakukan agar status hidrasi atlet pun tetap dalam keadaan yang baik. Menurut (Dieny \& Putriana, 2015) bahwa konsumsi air saja tidak menstimulasi rasa ingin minum dan dapat meningkatkan jumlah urin yang keluar dan menyebabkan penurunan asupan. Minuman yang direkomendasikan untuk menjaga status hidrasi adalah minuman yang mengandung 
karbohidrat dan elektrolit, diantaranya jus buah, jus sayur, susu, dan sport drink.

Menurut (Murray, 2007) hidrasi diartikan sebagai keseimbangan cairan dalam tubuh dan merupakan syarat penting untuk menjamin fungsi metabolisme sel tubuh. Konsumsi cairan merupakan cara untuk menyeimbangkan homestatis di dalam tubuh ketika beraktivitas. Berbagai macam minuman secara keilmuan telah dipertimbangkan untuk dapat meningkatkan dan menyeimbangkan status hidrasi. Menurut (Murray, 2007) konsumsi minuman ideal untuk berolahraga yaitu minuman olahraga dan jus buah (encer).

Pocari sweat merupakan minuman isotonik dan sudah banyak dikonsumsi ketika berolahraga. pocari sweat memiliki komposisi mirip dengan cairan tubuh sehingga diserap lebih cepat dan cepat gantikan cairan dan ion tubuh yang hilang. Manfaat bagi tubuh itu sendiri baik karena cepat mengembalikan ion yang hilang akibat aktivitas. Penelitian mengenai warna urin yang dilakukan Flora \& Soempeno (2005) membuktikan bahwa ada pengaruh dari pemberian pocari sweat terhadap perubahan warna urin dalam proses rehidrasi pada atlet yang dibuktikan dengan perubahan yang signifikan sebelum dan setelah exercise pada atlet.

Buah semangka merupakan buah dengan kadar air di dalamnya sangat banyak. (Arifianto, 2008) mengungkapkan bahwa di dalam 100 gram buah semangka memiliki kandungan air sebanyak 92,1\% dan kandungan karbohidrat 6,9 gram. Manfaat buah semangka telah terbukti dengan beberapa penelitian terdaulu yang telah dilakukan. Salah satu penelitian yang membuktikan bahwa buah semangka memiliki manfaat bagi olahraga adalah penelitian yang dilakukan Sirait et al., (2015), dibuktikan bahwa terdapat pengaruh pemberian jus semangka terhadap kelelahan otot dan delayed onset muscle soreness setelah latihan beban.

Penelitian ini dilakukan untuk melihat perbedaan pengaruh dari jus semangka dan minuman isotonik terhadap status hidrasi. Status hidrasi yang menunjukkan keadaan normal sangat penting bagi para pelaku olahraga. Terutama bagi atlet olahraga prestasi dengan karakteristik cabang olahraga daya tahan. Penelitian ini mencoba untuk melihat efek dari pemberian konsumsi jus semangka dan minuman isotonik. Pengumpulan data status hidrasi menggunakan instrumen Urinalysis Multisticks Urine Strip Test Stick Strips dengan menggunakan metode pengukuran berat jenis urin yang sesuai dengan variabel yang diukur.

Hasil temuan penelitian menunjukan perubahan rata-rata nilai berat jenis urin pada treatment jus semangka sebesar $-1,167 \mathrm{~g} / \mathrm{dl}$ dan pada treatment minuman isotonik sebesar 1,33 g/d1. Secara perhitungan statistik, kedua treatment tersebut menunjukan tidak adanya peningkatan secara signifikan $(p>0,05)$ antara sebelum dan sesudah diberikannya treatment. Sedangkan nilai signifikansi antara treatment jus semangka dan treatment minuman isotonik diperoleh sebesar 0,461 . Secara perhitungan statistika, menunjukan tidak adanya perbedan secara signifikan $(p>0,05)$ antara treatment jus semangka dan treatment minuman isotonik. Hasil tersebut diraih dari hasil perlakuan yang diberikan kepada sampel yakni pemberian jus semangka dan minuman isotonik sebanyak 100 $\mathrm{ml}$ sebanyak $6 \mathrm{x}$ pemberian dengan waktu latihan selama 2 jam pada periode yang berbeda dimana setiap periode berdurasi 1 minggu. Berdasarkan hasil tersebut, diketahui bahwa tidak adanya penurunan nilai berat jenis urin secara signifikan dikarenakan volume yang dikonsumsi yang hanya $100 \mathrm{ml}$. Hidayat (2014) menyebutkan bahwa konsumsi cairan ketika berolahraga adalah $250 \mathrm{ml}$ setiap 20 menit.

Dari ketiga perhitungan secara statistika diatas dan merujuk kepada beberapa teori yang berkaitan dengan berat jenis urin dan melihat dari hasil penelitian sebelumnya yang relevan, dapat disimpulkan bahwa pemberian jus semangka dan minuman isotonik sama-sama menjaga status hidrasi dan mencegah terjadinya dehidrasi, akan tetapi tidak ada perbedaan pengaruh antara jus semangka dan minuman isotonik terhadap status hidrasi. Tidak adanya perbedaan rata-rata antara pengaruh jus semangka dan minuman isotonik menunjukkan bahwa jus semangka bisa dijadikan sebagai 
alternatif minuman pada saat olahraga. Maka dari itu, jus semangka dapat dijadikan alternatif pengganti pocari sweat sebagai minuman olahraga. Selain menggunakan bahan alami, jus semangka memiliki lebih banyak keuntungan lain seperti yang tertulis dalam penelitian yang telah dilakukan sebelumnya. Lubis \& Siregar (2017) melakukan penelitian yang berjudul pengaruh pemberian semangka terhadap denyut nadi pemulihan setelah melakukan aktivitas fisik pada siswa Paskibra SMA Negeri 4 Medan. Tujuan penelitian ini adalah untuk mengetahui pengaruh pemberian semangka terhadap denyut nadi pemulihan setelah melakukan aktivitas fisik pada siswa Paskibra SMA Negeri 4 Medan. Penelitian ini menggunakan metode quasi eksperimen. Penelitian ini dilaksanakan di lapangan JASDAM Gaperta Jl.Gaperta, Helvetia Tengah, Medan Helvetia, Kota Medan, Sumatera Utara. Populasi penelitian ini berjumlah 55 orang dengan jumlah sampel 16 orang kelompok eksperimen berjumlah 8 orang dan kelompok kontrol 8 orang diambil dengan purposive random sampling. Dari hasil uji $t$ berpasangan menunjukkan hasil rata-rata denyut nadi pemulihan kelompok pre test eksperimen sebesar 92,50 sedangkan post test sebesar 78,75 dengan nilai $p=0,008$ yang berarti ada pengaruh pemberian semangka bterhadap denyut nadi pemulihan setelah melakukan aktivitas fisik. Sedangkan pada kelompok kontrol memperoleh nilai rata-rata pre test sebesar 90,00 sedangkan post test sebesar 93,75 dengan nilai $\mathrm{p}=0,080$ yang berarti tidak ada pengaruh pada kelompok kontrol. Hasil uji $t$ tidak berpasangan menunjukkan nilai $\mathrm{p}=0,004$ dengan demikian adanya pengaruh signifikan pemberian semangka terhadap denyut nadi pemulihan dengan $(p<0,05)$. Penelitian ini menyimpulkan bahwa kelompok yang diberikan semangka memberi pengaruh yang signifikan terhadap denyut nadi pemulihan pada siswa Paskibra SMA Negeri 4 Medan.

(Hasanah, 2015) melakukan penelitian yang berjudul perbedaan nilai kelelahan anaerobik atlet sepakbola yang diberikan dan tidak diberikan buah semangka merah (Citrullus lanatus). Penelitian ini bertujuan untuk mengetahui perbedaan nilai kelelahan anaerobik atlet sepakbola yang diberikan buah semangka merah dan yang tidak diberikan buah semangka merah. Penelitian ini merupakan penelitian quasi experiment dengan rancangan post test only with control group design. Subjek penelitian adalah 20 orang atlet laki-laki usia 1518 tahun yang memenuhi kriteria inklusi, dibagi menjadi 2 kelompok, kelompok kontrol dan kelompok perlakuan. Kelompok kontrol diberikan plasebo berupa sirup bebas gula dan kelompok perlakuan diberikan buah semangka dengan dosis 72 gram. Buah semangka diberikan 60 menit sebelum tes dilakukan. Pengukuran kelelahan anaerobik menggunakan tes Wingate dinyatakan dalam nilai Anaerobic Fatigue (AF). Hasil penelitian ini pada karakteristik subjek tidak ada perbedaan umur dan status gizi $(p>0,05)$ namun terdapat perbedaan persen lemak tubuh $(p<0,05)$. Sebagian besar subjek memiliki status gizi normal dan persen lemak tubuh baik. Pada asupan sarapan pagi tidak ada perbedaan rata-rata asupan energi, lemak, karbohidrat, dan protein sarapan $(p>0,05)$. Berdasarkan uji Independent-t, terdapat perbedaan nilai kelelahan anaerobik pada kelompok perlakuan yaitu sebesar 80,04\% sedangkan pada kelompok kontrol sebesar $82,71 \%$. Kesimpulan dari penelitian ini terdapat perbedaan nilai kelelahan anaerobik atlet sepakbola yang diberikan buah semangka dan yang tidak diberikan buah semangka.

(Sirait et al., 2015) melakukan penelitian yang berjudul pengaruh pemberian jus semangka terhadap kelelahan otot dan delayed onset muscle soreness setelah latihan. Penelitian ini bertujuan untuk mengetahui pengaruh pemberian jus semangka terhadap berkurangnya kelelahan otot dan delayed onset muscle soreness (DOMS) setelah latihan beban. Kelelahan otot diukur menggunakan jumlah repetisi maksimal yang dapat dilakukan peserta pada set terakhir dan DOMS diukur menggunakan intensitas nyeri otot yang muncul setelah latihan. Sebanyak 20 orang peserta dibagi menjadi 2 kelompok yaitu kelompok perlakuan dan kelompok kontrol yang dipilih secara random dan dilakukan cross over. Peserta 
diminta melakukan protokol latihan untuk menginduksi kelelahan otot dan DOMS. Sebanyak $500 \mathrm{~mL}$ jus semangka dikonsumsi pada 1 dari 2 sesi latihan, sedangkan pada sesi latihan berikutnya digunakan plasebo. Hasil uji t-paired test jumlah repetisi set ke-3 peserta didapatkan $\mathrm{p}<0,05$ yang artinya terdapat perbedaan bermakna antara kelompok kontrol dan kelompok perlakuan setelah diberikan jus semangka. Hasil uji wilcoxon signed ranks test intensitas nyeri otot aktif peserta didapatkan hasil pada 30 menit setelah latihan $\mathrm{p}=0,083$ serta 24 jam dan 48 jam setelah latihan $p=0,000$. Hasil uji analisis data didapatkan $\mathrm{p}=0,05$ yang artinya terdapat perbedaan bermakna antara kelompok kontrol dan kelompok perlakuan setelah diberikan jus semangka. Dari penelitian ini dapat disimpulkan terdapat efek pemberian jus semangka terhadap kelelahan otot dan DOMS setelah latihan beban.

Dari penjelasan beberapa penelitian diatas menguatkan bahwa konsumsi jus semangka dapat menjaga status hidrasi, mengurangi tingkat kelelahan otot, menurunkan tekanan darah, nilai kelelahan anaerobik yang kecil dan memulihkan denyut nadi lebih baik setelah beraktivitas (Lubis \& Siregar, 2017; Shanti \& Zuraida, 2016; Sirait et al., 2015).

\section{KESIMPULAN}

Pemberian jus semangka dan minuman isotonik dapat menjaga status hidrasi dan mencegah terjadinya dehidrasi pada atlet futsal, akan tetapi tidak ada perbedaan pengaruh pemberian jus semangka dan minuman isotonik terhadap status hidrasi. Oleh karena itu, jus semangka bisa dijadikan sebagai alternatif lain untuk digunakan sebagai minuman pada saat berolahraga.

\section{Implikasi}

Hasil dari penelitian yang telah dilaksanakan menunjukkan bahwa tidak adanya perbedaan pengaruh dari kedua treatment terhadap status hidrasi atlet futsal. Implikasi dari penelitian ini meliputi beberapa hal yang dapat dimanfaatkan oleh berbagai pihak. Implikasinya adalah sebagai berikut :
Penjelasan dan instrumen pengukuran status hidrasi dapat digunakan sebagai acuan untuk sampel yang lebih umum seperti masyarakat yang notabennya bukan atlet. Implikasi dari penelitian ini diharapkan dapat menambah wawasan dan pengetahuan bagi semua orang untuk mengetahui bagaimana menjaga status hidrasi dan menghindari terjadinya dehidrasi sebagai alat untuk memudahkan diri mengetahui tingkat hidrasi khsusunya pada atlet. Tidak ada perbedaan pengaruh pemberian jus semangka dan minuman isotonik terhadap status hidrasi, maka dari itu hasil penelitian ini bisa dijadikan pertimbangan dan masukan untuk mengkonsumsi jus semangka yang berasal dari bahan alami sebagai minuman olahraga.

\section{Rekomendasi}

Dari uraian implikasi penelitian, peneliti bermaksud untuk mengemukakan beberapa hal terkait rekomendasi. Rekomendasi yang diajukan oleh peneliti yang sekiranya dapat bermanfaat dalam membantu memberikan gambaran mengenai peningkatan status hidrasi. Berdasarkan hal tersebut peneliti merekomendasikan beberapa hal untuk penelitian selanjutnya diantaranya; 1) bagi peneliti yang akan melakukan penelitian selanjutnya yang serupa, agar lebih memperhatikan faktor-faktor yang dapat mempengaruhi status hidrasi seperti banyaknya minum yang harus diberikan kepada sampel ketika latihan, waktu yang tepat pada saat memberikan minuman ketika latihan dan status gizi yang terlebih dahulu harus diketahui, 2) Peneliti merekomendasikan agar melakukan penelitian dengan memperbanyak penggunaan sampel dan memperluas sampel pada penelitian baik atlet maupun non atlet, 3) Peneliti selanjutnya diharapkan dapat bersikap tegas dan dapat memotivasi sampel dengan baik agar dapat berkonsisten dengan program penelitian yang telah diberikan, 4) Peneliti merekomendasikan agar lembaga AFKOT (Asosisasi Futsal Kota Cimahi) untuk lebih memperhatikan asupan cairan ketika latihan sedang berlangsung. 


\section{DAFTAR PUSTAKA}

Arifianto, N. (2008). Consumers preference towards watermelon in semarang. Jurnal Ilmu-Ilmu Pertanian, 4(2), 75-85

Damayanti, I., \& Rahayu, N. I. (2017). The Effect of Muslim Women's Sportswear (Jilbab) to Dehydration Level and Thermoregulation After Exercise. IOP Conference Series: Materials Science and Engineering, 180(1). https://doi.org/10.1088/17426596/755/1/011001

Dieny, F. F., \& Putriana, D. (2015). Status hidrasi sebelum dan sesudah latihan atlet sepak bola remaja. Jurnal Gizi Indonesia, 3(2), 86-93.

Dwita, L. P., Amalia, L., Iwo, M. I., \& Bahri, S. (2015). Pengaruh Rehidrasi Menggunakan Air Kelapa (Cocos Nucifera L) Terhadap Stamina Atlet Dayung. Farmasains, 2(5), 229-233.

Farrow, D., \& Mujika, I. (2007). Fatigue in tennis: Mechanisms of fatigue and effect on performance.

FLORA, R., \& Soempeno, B. (2005). Efektivitas minuman suplemen dalam mengembalikan keseimbangan cairan tubuh pada dehidrasi akibat aktivitas aerobik intensitas sedang. Universitas Gadjah Mada.

Hasanah, U. (2015). Perbedaan nilai kelelahan anaerobik atlet sepakbola yang diberikan dan tidak diberikan buah semangka (Citrullus lanatus). Universitas Diponegoro Semarang.

Hermans, V., Gdawietz, G., Engler, R., \& Schwehm, W. (2010). Futsal: Technique, Tactics, Training. Diambil dari http://books.google.com/books?hl=en\&lr= \&id=M7YwdMypwhUC\&oi=fnd\&pg=PA9 $\& d q=$ Futsal + Technique+Tactics + Training \& ots $=611 \mathrm{XqKk} 8 \mathrm{Db} \&$ sig $=\mathrm{MKbBK}$ EBcpkyCsMovCsnUIBZQ2k

Hidayat. (2014). E-Book Pemenuhan Kebutuhan Cairan.pdf. (Tim Penulis PDSKO, Ed.) (Pertama). Jakarta: PDSKO.

Irawan, M. A. (2007). Nutrisi, Energi, \& Performa olahraga. Polton Sport Science \& Performance Lab, 1, 1-13.

Jones, B., \& Kenward, M. G. (2014). Design and analysis of cross-over trials. CRC press.

Junaidi, I. (2013). ENSIKLOPEDIA JUS, SAYUR, DAN BUAH. Bhuana Ilmu Populer.

Katch, V. L., Katch, F. I., \& McArdle, W. D. (1994). Student study guide and workbook for essentials of exercise physiology. Fitness Technologies Press.
Lhaksana, J. (2011). Taktik \& Strategi futsal modern. Be Champion.

Lubis, R. F., \& Siregar, N. S. (2017). Pengaruh Pemberian Semangka Terhadap Denyut Nadi Pemulihan Setelah Melakukan Aktivitas Fisik. Sains Olahraga: Jurnal Ilmiah Ilmu Keolahragaan, 1(1).

Murhananto. (2006). Dasar-dasar Permainan Futsal. Jakarta: Kawan Pustaka. Diambil dari https://books.google.co.id/books?id=IlGUO Tt_XvoC

Murray, B. (2007). Hydration and physical performance. Journal of the American College of Nutrition, 26(sup5), 542S-548S.

Setiawan, M. I. (2016). Pengaruh Pemberian Jus Semangka Kuning ( Citrulus Lanatus ) Terhadap Konsumsi Oksigen Maksimal ( Vo 2 Max ) Pada Atlet Sepak Bola. Universitas Diponegoro Semarang.

Shalesh, F. J., Hasan, U. C. H., \& Jaaz, A. F. (2014). The effect of sport drink on some functional variables for soccer players. Internasional Journal Of Advanced Research, 2(2), 868875.

Shanti, N. M., \& Zuraida, R. (2016). Pengaruh Pemberian Jus Semangka Terhadap Penurunan Tekanan Darah Lansia. Majority, 5(4), 117-123. Diambil dari http://juke.kedokteran.unila.ac.id/index.php /majority/article/viewFile/896/804

Sirait et al. (2015). Pengaruh Pemberian Jus Semangka terhadap Kelelahan Otot dan Delayed Onset Muscle Soreness setelah Latihan Beban (The effect of Watermelon Juice on Muscle Fatigue and Delayed Onset Muscle Soreness after Weight Training). EJurnal Pustaka Kesehatan, 1, 132-135.

Sugiyono, M. P. K. (2008). kualitatif dan R\&D. Bandung: Alfabeta, 124.

Sulistomo, A., Sutarina, N., \& Ilyas, E. (2014). Hidrasi pada aktivitas khusus. Status hidrasi pada kondisi umum dan khusus. Jakarta: Badan Penerbit FK UI, 60-81.

Zanzer, Y. C. (2011). (Epigallocatechin gallate ) TEH HIJAU DALAM MENGONTROL LEVEL GLUKOSA PLASMA DARAH POSTPRANDIAL. Institut Pertanian Bogor. 